\title{
Effects of Stand Origin and Near-Natural Restoration on the Stock and Structural Composition of Fallen Trees in Mid-Subtropical Forests
}

\author{
Chunsheng $\mathrm{Wu}^{1}{ }^{1}$, Xiaohua Wei ${ }^{2}$, Qifeng Mo ${ }^{3}$, Qinglin Li ${ }^{4}$, Xiaodong $\mathrm{Li}^{1}{ }^{1}$, Chunjie Shu ${ }^{1}$, \\ Liangying Liu ${ }^{1}$ and Yuanqiu Liu ${ }^{1, *}$ \\ Received: 30 September 2015; Accepted: 26 November 2015; Published: 3 December 2015 \\ Academic Editor: Mark E. Harmon \\ 1 College of Forestry, Jiangxi Agricultural University, 1101 ZhiMin Road, Nanchang 330045, China; \\ woaijxau@163.com (C.W.); laoli847@126.com (X.L.); spring3462@163.com (C.S.); wcsscj0109@126.com (L.L.) \\ 2 Earth and Environmental Science, University of British Columbia (Okanagan), 1177 Research Road, \\ Kelowna, BC V1V 1V7, Canada; adam.wei@ubc.ca \\ 3 Key Laboratory of Vegetation Restoration and Management of Degraded Ecosystems, South China Botanical \\ Garden, Chinese Academy of Sciences, Xingke Road 723, Tianhe District, Guangzhou 510650, China; \\ moqifeng@scib.ac.cn \\ 4 School of Forestry and Bio-Technology, Zhejiang A \& F University, Lin'an 311300, China; \\ Qinglin.li@gov.bc.ca \\ * Correspondence: liuyq404@163.com; Tel.: +86-151-7001-1285
}

\begin{abstract}
Fallen trees comprise an important part of forest ecosystems and serve a central role in maintaining the biodiversity and tree regeneration of forests. However, the effects of stand origin and near-natural restoration on the biomass and carbon stock of fallen trees remain unclear. Based on 60 sampling plots of field surveys of mid-subtropical forests in Jiangxi Province, we investigated the stock and structural composition of fallen trees in artificial coniferous forests (Acf), natural coniferous forests $(\mathrm{Ncf})$ (e.g., different stand origins) and natural evergreen broadleaf forests (Nebf) (e.g., near-natural restoration). The following results were obtained: (1) the largest biomass and carbon stocks of fallen trees among three forest types (Nebf, Ncf and Acf) were measured for Nebf; (2) the fallen tree biomass and carbon stock in natural Cunninghamia lanceolata forest (Nclf) were significantly larger than that in artificial Cunninghamia lanceolata forest (Aclf), and the fallen tree biomass and carbon stock in natural Pinus massoniana forest (Npf) were also significantly larger than those in artificial Pinus massoniana forest (Apf); (3) the diameter class allocation in natural forests was more uniform than that in artificial forests; (4) the biomass of fallen trees with mild decay was not significantly different among forest types within stand origin or among the stand origin within forest types; however, the biomass of fallen trees with moderate and heavy decay significantly differed among stand origin (Aclf vs. Nclf, Apf vs. Npf), but was not significant among the forest types (Aclf vs. Apf, Nclf vs. Apf) within a stand origin. Our results suggested that the large biomass and carbon stock of fallen trees in Nebf may serve a significant role in mitigating global warming and carbon cycles in mid-subtropical forests. Therefore, stand origin and near-natural restoration exert significant effects on the carbon stock and structural composition of fallen trees in mid-subtropical forests.
\end{abstract}

Keywords: fallen tree; carbon; subtropical forest; stand origin; near-natural restoration

\section{Introduction}

Fallen trees are an important part of forests and can be regarded as carbon and nutrient pools, which serve a crucial role in the biogeochemical cycles and global carbon balance in forest ecosystems. Fallen trees can sustain the stability and biodiversity of forest ecosystems and are beneficial to the 
maintenance of primary productivity and sustainable development [1-3]. Therefore, the rational utilization and protection of fallen trees should be central to the sustainable operation and management of forest ecosystems. However, the roles of fallen trees in mitigating global climates and enhancing forest functions have been a significant concern of global ecologists [2-5].

The carbon storage of fallen trees in global forests is $(2.0-16.0) \times 10^{10} \mathrm{mg}$, which accounts for $1.75 \%-13.96 \%$ of the carbon stock in the global forest ecosystem $\left(114.6 \times 10^{11} \mathrm{mg}\right)$ [6]. Thus, in order to make a complete estimation of carbon storage in forest ecosystem, the biomass of fallen trees must be considered [7]. Previous studies have demonstrated that disturbance, competition, forest type and stand age significantly affect not only the biomass of fallen trees in forest ecosystems, but also the decomposition and structure of fallen trees [8,9]. Thus, investigation of the direct and indirect effects of external factors (disturbance, competition, forest type and stand age) on the biomass, decomposition and structure of fallen trees is relatively important for the carbon storage and functional balance in forest ecosystems.

The structure and function of a natural forest is more complex and comprehensive than the structure and function of an artificial forest in terrestrial ecosystems [10]. Due to the deforestation of natural forests, a large number of artificial forests have been expanded to satisfy the demand for wood produce. According to the results from the Seventh National Forest Resource Inventory, the artificial plantation maintains the largest area in forest at $6.16 \times 10^{7}$ ha, which accounts for $34.01 \%$ of the forest land area in China. Moreover, the artificial forest stock is $1.961 \times 10^{10} \mathrm{~m}^{3}$, which accounts for $14.67 \%$ of the total forest stock in China (e.g., ranked first in the world) [11]. However, the structure, function and stability of an artificial forest substantially differs from the structure, function and stability of a natural forest [11,12]. It is believed that artificial forests in China usually have larger planting density with more similarly-aged trees, and the largest number of fallen trees in artificial forests originates from the disturbance of afforestation, human operation management, intra competition and natural pruning [13]. However, natural forests in China have primarily diversely-aged trees and are less disturbed by human management and afforestation. The larger number of fallen trees in natural forests can be attributed to natural competition, density adjustment and natural pruning. Death by aging and external disturbances (e.g., wind, snowstorms, lightning, fire, pests and diseases) causes significant differences in the biomass stock and structure between natural forests and artificial forests [9,14-17].

This study was conducted to assess the storage, diameter class distribution and decomposition condition of fallen trees in natural coniferous forests $(N c f)$, artificial coniferous forests $(A c f)$ and natural evergreen broadleaf forests (Nebf) in Jiangxi Province of mid-subtropical China. We pose the following questions: (1) Are there any differences in the biomass of fallen trees among Acf, Ncf and Nebf? (2) Are there any structural differences in stand origin (Acf and $N c f)$ and near-natural restoration ( $N c f$ and Nebf) in these forest types?

\section{Materials and Methods}

\subsection{Study Site}

The study area is located in Jiangxi Province of mid-subtropical China $\left(24^{\circ} 29^{\prime} \sim 30^{\circ} 05^{\prime} \mathrm{N}\right.$ and $113^{\circ} 34^{\prime} \sim 118^{\circ} 29^{\prime}$ E). The climate is characterized as humid sub-tropic monsoon, and the soil is predominantly acidic and red. The annual average temperature is $18.9^{\circ} \mathrm{C}$ and the precipitation amount is $1438 \mathrm{~mm}$. The dominant vegetation types primarily include evergreen broadleaf forests (e.g., Cinnamomum camphora, Schima superba and Castanopsis sclerophylla), deciduous broadleaf forests (e.g., Alniphyllum fortunei, Choerospondias axillaris and Liquidambar formosana), coniferous forests (e.g., Pinus massoniana, Cunninghamia lanceolata and Pinus elliottii), and bamboo forests (e.g., Phyllostachys heterocycla) [18]. In this study, the fallen trees of artificial coniferous forests (including artificial Cunninghamia lanceolata forests and artificial Pinus massoniana forests), natural coniferous forests (including natural Cunninghamia lanceolata forests and natural Pinus massoniana forests) and natural evergreen broadleaf forests (a total of 60 sample plots) were selected (Table 1). The plot size was 
$28.28 \mathrm{~m} \times 28.28 \mathrm{~m}(0.08 \mathrm{ha})$.We measured the central diameter and length of a fallen tree, then recorded the decay class of fallen trees with diameter $\geqslant 2.5 \mathrm{~cm}$ in each sample plot. Each structural class (\%) of standing tree based on diameter for different stand types was recorded (Table A1). A short section of each fallen tree was sampled to bring back to the laboratory for physical and chemical analysis.

Table 1. General status of the experimental plots.

\begin{tabular}{cccccccc}
\hline $\begin{array}{c}\text { Forest } \\
\text { Types }\end{array}$ & $\begin{array}{c}\text { Stand } \\
\text { Types }\end{array}$ & $\begin{array}{c}\text { Number } \\
\text { of Plots }\end{array}$ & $\begin{array}{c}\text { Average } \\
\text { Age (Years) }\end{array}$ & $\begin{array}{c}\text { Average Stand } \\
\text { Density (Stems/hm }{ }^{2} \text { ) }\end{array}$ & $\begin{array}{c}\text { Average Canopy } \\
\text { Cover (\%) }\end{array}$ & $\begin{array}{c}\text { Average } \\
\text { DBH (cm) }\end{array}$ & $\begin{array}{c}\text { Average } \\
\text { Height (m) }\end{array}$ \\
\hline \multirow{2}{*}{ Acf } & Aclf & 10 & 20.8 & $1877 \pm 615$ & $75 \pm 10$ & $10.3 \pm 2.8$ & $10.7 \pm 1.5$ \\
& Apf & 10 & 20.3 & $1252 \pm 599$ & $64 \pm 16$ & $9.39 \pm 2.9$ & $9.11 \pm 2.8$ \\
Ncf & Nclf & 10 & 20.5 & $1559 \pm 402$ & $60 \pm 15$ & $10.21 \pm 2.1$ & $9.48 \pm 1.8$ \\
NEbf & Npf & 10 & 20.1 & $887 \pm 487$ & $62 \pm 17$ & $12.2 \pm 4.9$ & $11.8 \pm 3.3$ \\
\hline
\end{tabular}

DBH, Diameter at breast height $1.3 \mathrm{~m}$ over bark; stems, number of trees; Acf, artificial coniferous forest; $N c f$, natural coniferous forest; NEbf, natural evergreen broad-leaved forest; Aclf, artificial Cunninghamia lanceolata forest; Apf, artificial Pinus massoniana forest; Nclf, natural Cunninghamia lanceolata forest; $\mathrm{Npf}$, natural Pinus massoniana forest. Values are shown with means \pm S.E.

\subsection{Decay Class of Fallen Trees}

Based on the standard established by Sollins [19] and the actual situation to classify different decay classes, the fallen trees of different forest types in our research area of Jiangxi province were divided into three different grades as follows:

Mild decay: bark, lateral branches of fallen trees were complete and sapwood was intact with mild decay.

Moderate decay: the majority of the bark had fallen off and part of the sapwood was decaying.

Heavy decay: no bark, a large area of sapwood and section heartwood were decaying.

\subsection{Carbon Content and Biomass Determination}

Using the weighting method to select the measuring number (e.g., a plurality of test samples) of fallen trees for each forest type, each test sample of a different decay class was repeated three times, and the carbon contents of the fallen trees were measured using a TOC analyzer (Vario TOC, Elementar, Germany).

The fresh weight of each fallen tree was directly measured using a steelyard $(\mathrm{kg}$, by two decimal places), Each tree under a drying process (e.g., drying at $65^{\circ} \mathrm{C}$ to obtain a consistent weight) to retrieve test samples (e.g., disks with a thickness range of 5-10 cm were extracted from each fallen tree) to calculate the dry weight and moisture content of the fallen trees and estimate the biomass of the fallen trees.

\subsection{Carbon Stock Calculations}

Density of fallen trees: First, the weights of the disks of the fallen trees were measured $(\mathrm{m}, \mathrm{g})$, and the disks were placed in a container with a specific amount of water in the container $\left(v_{1}, \mathrm{~mL}\right)$, the volume of water $\left(v_{2}, \mathrm{~mL}\right)$, and the densities of the fallen trees $\left(\rho, \mathrm{g} / \mathrm{cm}^{3}\right)$ were calculated (Equation (1)).

$$
\rho=\mathrm{m} /\left(v_{1}-v_{2}\right)
$$

Volume of fallen trees: A central cross section approximation was utilized to calculate the volume [20] as:

$$
V_{L D W_{\mathrm{ij}}}=\left(\pi D_{L D W_{i j}}{ }^{2} \times h_{L D W_{i j}}\right) / 4
$$

where, $V_{L D W_{i j}}\left(\mathrm{~m}^{3}\right)$ represents the volume of fallen trees with decay class $\mathrm{j}$ (e.g., $\mathrm{j}=1,2,3$ represent mild decay, moderate decay and heavy decay, respectively), $D_{L D W_{i j}}(\mathrm{~cm})$ is the central diameter and $h_{L D W_{i j}}(\mathrm{~m})$ represents the lengths of the fallen trees. 
The morphologies of the fallen trees were examined to classify the different decaying classes. The volume, density, and carbon content of each corresponding sample were employed to calculate the carbon stock for the fallen trees (Equation (3)).

$$
C_{D W_{i}}=\sum_{j=1}^{3}\left[V_{L D W_{i, j}} \times D_{L D W_{i, j}} \times C F_{L D W_{i, j}}\right]
$$

where, $C_{D W_{i}}$ is carbon storage of the $i$ th fallen tree in the ecosystem, and the carbon stock of $C_{L D W_{i j}}$. The units are $\mathrm{mg} / \mathrm{ha}$.

$V_{L D W_{i j}}\left(\mathrm{~m}^{3}\right)$ is the volume of fallen trees with decay class $\mathrm{j}$ (e.g., $\mathrm{j}=1,2,3$ represent mild decay, moderate decay and heavy decay, respectively). $D_{L D W_{i j}}\left(\mathrm{~g} / \mathrm{cm}^{3}\right)$ represents the densities of the fallen trees in different decay classes, and $C F_{L D W_{i j}}(\mathrm{~g} / \mathrm{kg})$ denotes the average carbon contents of fallen trees in different decay classes.

\subsection{Statistical Analysis}

Statistical analyses were conducted using SPSS 17.0 software (IBM company, Chicago, IL, USA), and a one-way analysis of variance (ANOVA) was employed to determine the differences among the biomass, carbon stock and diameter class of three forest types (Acf, Ncf vs. NEbf) and two different stand types (artificial and natural). A one-way ANOVA was also performed to determine the significant differences among the carbon stocks of the same forest type and different stand types (artificial forests and natural forests) between the different decay classes. The least significant difference (LSD) was calculated when the treatments significantly differed.

\section{Results}

\subsection{Biomass and Carbon Stock of Fallen Trees in Artificial and Natural Forests}

The biomass of fallen trees in Ncf $\left(1.625 \pm 0.22 \mathrm{t} / \mathrm{hm}^{2}\right)$ was significantly higher than that in Acf $\left(0.813 \pm 0.25 \mathrm{t} / \mathrm{hm}^{2}\right)$, and Acf yielded a significant reduction compared with the Nebf climax forests $\left(11.061 \pm 1.15 \mathrm{t} / \mathrm{hm}^{2}\right)$ (Figure 1). The carbon storage of fallen trees in Nebf $\left(4.735 \pm 0.33 \mathrm{mg} / \mathrm{hm}^{2}\right)$ was significantly higher than that in $N c f\left(0.647 \pm 0.08 \mathrm{mg} / \mathrm{hm}^{2}\right)$, and in $N c f$ was also significantly higher than that in $A c f\left(0.255 \pm 0.07 \mathrm{mg} / \mathrm{hm}^{2}\right)$ (Figure 1).

The biomass and carbon stock of fallen trees in Nclf was significantly higher than that in Aclf, and the biomass and carbon stock of fallen trees in Npf was also significantly larger than that in Apf (Table 2). However, no significant differences between Aclf and Apf and, Nclf and Npf were observed (Table 2).

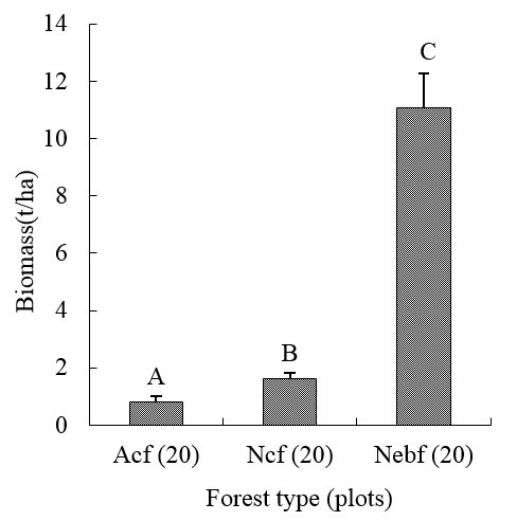

a

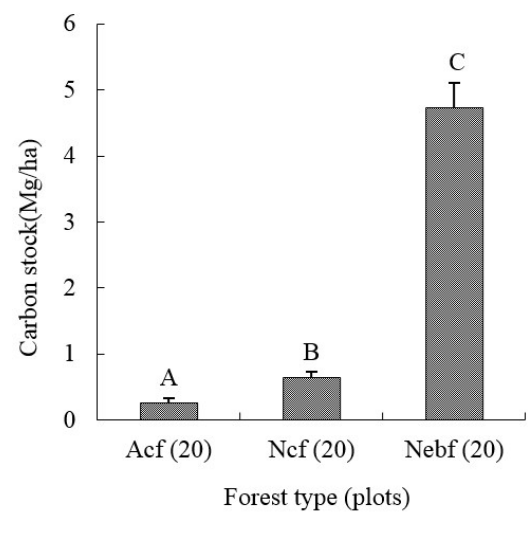

b

Figure 1. Biomass (a) and carbon stock (b) of fallen trees in artificial and natural forest. Acf, artificial coniferous forest; $N c f$, natural coniferous forest; $N E b f$, natural evergreen broad-leaved forest; Different uppercase letters indicate significant differences among different forest types (Acf, Ncf or Nebf) at $p<0.05$. 
Table 2. Biomass and carbon stock of fallen trees for different stand and forest types.

\begin{tabular}{ccc}
\hline Stand Types (Plots) & Biomass (t/ha) & Carbon Stocks (mg/ha) \\
\hline Aclf (10) & $0.424 \pm 0.06 \mathrm{a}^{\mathrm{A}}$ & $0.143 \pm 0.04 \mathrm{a}^{\mathrm{A}}$ \\
Nclf (10) & $0.815 \pm 0.17 \mathrm{~b}^{\mathrm{A}}$ & $0.329 \pm 0.09 \mathrm{~b}^{\mathrm{A}}$ \\
Apf (10) & $0.389 \pm 0.08 \mathrm{a}^{\mathrm{A}}$ & $0.112 \pm 0.05 \mathrm{a}^{\mathrm{A}}$ \\
Npf (10) & $0.810 \pm 0.14 \mathrm{~b}^{\mathrm{A}}$ & $0.318 \pm 0.08 \mathrm{~b}^{\mathrm{A}}$ \\
\hline
\end{tabular}

Different uppercase letters indicate significant differences among different forest types (Cunninghamia lanceolata, Pinus massoniana) of the same stand type (artificial or natural) at $p<0.05$. Different lowercase letters indicate significant differences among different stand types for the same forest type $(p<0.05)$.

\subsection{Fallen Trees Diameter Class Structure of Artificial and Natural Forests}

According to the diameter class distribution of fallen trees in subtropical forests, the diameter class was divided into five grades (e.g., $0-5 \mathrm{~cm}, 5-10 \mathrm{~cm}, 10-15 \mathrm{~cm}, 15-20 \mathrm{~cm}$ and $\geqslant 20 \mathrm{~cm}$ (upper limit exclusion)) with intervals of $5 \mathrm{~cm}$, which refer to diameter classes I, II, III, IV, and V.

The diameter class distributions of the biomass of fallen trees between natural forests and artificial forests significantly differed (Figure 2). The biomass of diameter class I exhibited no significant difference among Acf, Ncf and Nebf, but demonstrated significant difference in diameter classes II, III and IV, with the consistent pattern Nebf $>N c f>A c f$ (Figure 2). The biomass of fallen trees with diameter I $(0-5 \mathrm{~cm})$ did not significantly differ among the stand origins within forest type (Aclf vs. Nclf, Apf vs. Npf) and within stand origin (Aclfvs. Apf, Nclf vs. Apf). However, the biomass of fallen trees with diameter class II, III and IV was significantly different among stand origins (Aclf vs. Nclf, Apf vs. Npf), but not significant among forest types within stand origin (Aclf vs. Apf, Nclf vs. Apf) (Table 3).

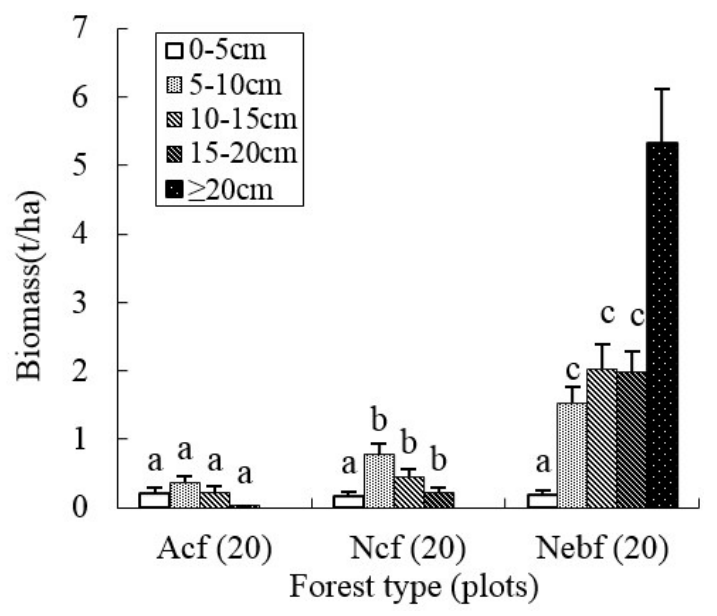

Figure 2. Biomass of fallen trees for different diameter classes in artificial and natural forests. Different lowercase letters indicate significant differences between different forest types (Acf, Ncf or Nebf) of the same diameter class $(p<0.05)$.

Table 3. Biomass of fallen trees by diameter class for different stand and forest types.

\begin{tabular}{ccccc}
\hline \multirow{2}{*}{ Stand Types (Plots) } & \multicolumn{4}{c}{ Diameter Class } \\
\cline { 2 - 5 } & I (0-5cm) & II (5-10cm) & III (10-15cm) & IV (15-20cm) \\
\hline Aclf (10) & $0.106 \pm 0.04 \mathrm{a}^{\mathrm{A}}$ & $0.218 \pm 0.08 \mathrm{a}^{\mathrm{A}}$ & $0.101 \pm 0.03 \mathrm{a}^{\mathrm{A}}$ & $0.017 \pm 0.08 \mathrm{a}^{\mathrm{A}}$ \\
Nclf (10) & $0.099 \pm 0.03 \mathrm{a}^{\mathrm{A}}$ & $0.424 \pm 0.14 \mathrm{~b}^{\mathrm{A}}$ & $0.217 \pm 0.08 \mathrm{~b}^{\mathrm{A}}$ & $0.119 \pm 0.04 \mathrm{~b}^{\mathrm{A}}$ \\
Apf (10) & $0.097 \pm 0.04 \mathrm{a}^{\mathrm{A}}$ & $0.153 \pm 0.05 \mathrm{a}^{\mathrm{A}}$ & $0.112 \pm 0.04 \mathrm{a}^{\mathrm{A}}$ & $0.009 \pm 0.003 \mathrm{a}^{\mathrm{A}}$ \\
Npf (10) & $0.091 \pm 0.02 \mathrm{a}^{\mathrm{A}}$ & $0.357 \pm 0.09 \mathrm{~b}^{\mathrm{A}}$ & $0.242 \pm 0.11 \mathrm{~b}^{\mathrm{A}}$ & $0.096 \pm 0.03 \mathrm{~b}^{\mathrm{A}}$ \\
\hline
\end{tabular}

Different uppercase letters indicate significant differences among different forest types (Cunninghamia lanceolata, Pinus massoniana) of the same stand type (artificial or natural) $(p<0.05)$. Different lowercase letters indicate significant differences among different stand types for the same forest type $(p<0.05)$. 
The results of the diameter class ratios for different forest types indicated that fallen trees of artificial forests are primarily distributed by small diameter classes less than $10 \mathrm{~cm}$ (I and II), which accounts for $86.7 \%$, but accounts only for $64.1 \%(\mathrm{Ncf})$ and $48.0 \%(\mathrm{Nebf})$ in natural forests (Table 4 ). In addition, the diameter class distribution in natural forests was relatively uniform compared with artificial forest (Table 4).

Table 4. The relative proportion of fallen trees across diameter classes.

\begin{tabular}{ccccc}
\hline \multirow{2}{*}{ Stand Types (Plots) } & \multicolumn{4}{c}{ Diameter Class Ratios } \\
\cline { 2 - 5 } & I (0-5 cm) & II (5-10 cm) & III (10-15 cm) & IV (15-20 cm) \\
\hline$A c f(20)$ & $38.5 \pm 5.1 \mathrm{a}$ & $48.2 \pm 5.7 \mathrm{~b}$ & $10.4 \pm 1.7 \mathrm{c}$ & $2.9 \pm 0.9 \mathrm{~d}$ \\
$N c f(20)$ & $14.6 \pm 4.2 \mathrm{a}$ & $49.5 \pm 5.5 \mathrm{~b}$ & $22.3 \pm 3.6 \mathrm{a}$ & $13.6 \pm 2.1 \mathrm{a}$
\end{tabular}

Different lowercase letters indicate significant differences among different diameter classes of the same forest type $(A c f, N c f$ or Nebf) $(p<0.05)$.

\subsection{Decomposition Differences of Fallen Trees in Artificial and Natural Forests}

The mild decay class of fallen trees (accounts for 61.8\%) was significantly higher than the remaining two decay classes (e.g., a moderate decay ratio, which accounts for $25.9 \%$ and a heavy decay ratio, which accounts for $12.3 \%$ ) in artificial forests; whereas the biomass for the moderate decay class of fallen trees (e.g., Ncf and Nebf accounts for $68.3 \%$ and $49.0 \%$, respectively) was significantly higher than that for the mild and heavy decay classes in natural forests (Figure 3). The biomass of fallen trees of mild, moderate and heavy decay classes in artificial forests significantly differed, while the biomass of fallen trees of moderate decay in Ncf and Nebf was significantly higher than those of mild and heavy decay (Figure 3). The biomass of fallen trees with mild decay was neither significant among forest types within stand origins nor among stand origin within forest type (Table 5); however, the biomass of fallen trees of moderate and heavy decay was significantly different among stand origins (Aclf vs. Nclf, Apf vs. Npf), but was not significant among forest types within stand origin (Aclf vs. Apf, Nclf vs. Apf) (Table 5).

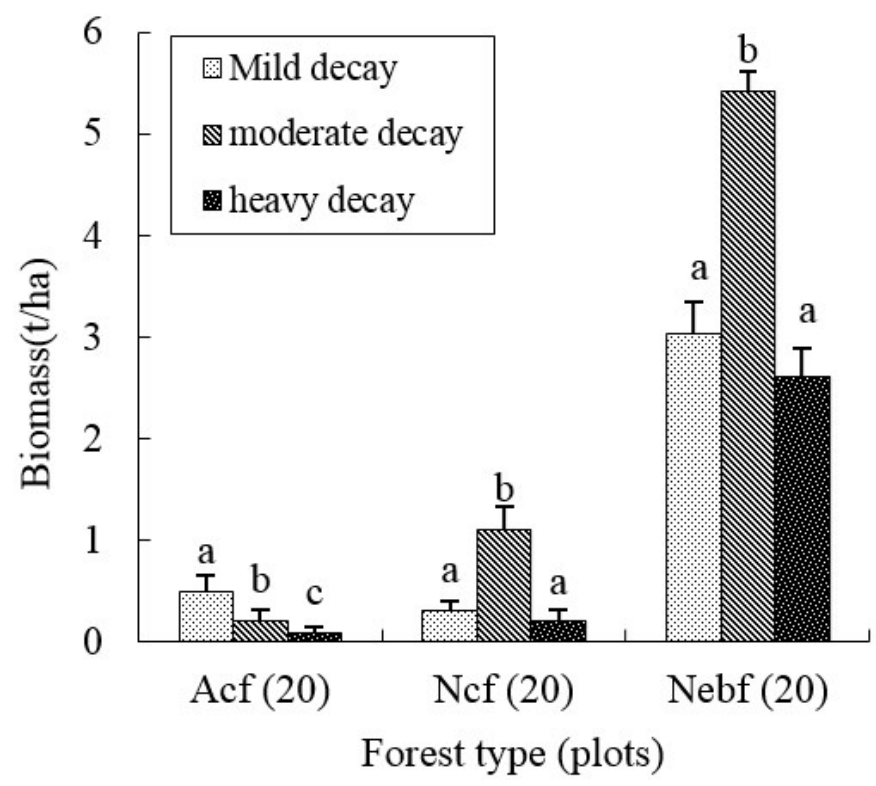

Figure 3. Biomass of fallen trees of different decay classes. Different lowercase letters indicate significant differences among different decay classes of the same forest type (Acf, Ncf or Nebf) $(p<0.05)$. 
Table 5. Biomass of fallen trees of decay classes in different stand and forest types.

\begin{tabular}{cccc}
\hline \multirow{2}{*}{ Stand Types (Plots) } & \multicolumn{3}{c}{ Decay Class } \\
\cline { 2 - 4 } & Mild Decay & Moderate Decay & Heavy Decay \\
\hline Aclf (10) & $0.274 \pm 0.08 \mathrm{a}^{\mathrm{A}}$ & $0.115 \pm 0.03 \mathrm{a}^{\mathrm{A}}$ & $0.058 \pm 0.01 \mathrm{a}^{\mathrm{A}}$ \\
Nclf (10) & $0.179 \pm 0.09 \mathrm{a}^{\mathrm{A}}$ & $0.539 \pm 0.13 \mathrm{~b}^{\mathrm{A}}$ & $0.121 \pm 0.03 \mathrm{~b}^{\mathrm{A}}$ \\
Apf (10) & $0.229 \pm 0.07 \mathrm{a}^{\mathrm{A}}$ & $0.096 \pm 0.01 \mathrm{a}^{\mathrm{A}}$ & $0.041 \pm 0.01 \mathrm{a}^{\mathrm{A}}$ \\
Npf (10) & $0.133 \pm 0.03 \mathrm{a}^{\mathrm{A}}$ & $0.571 \pm 0.15 \mathrm{~b}^{\mathrm{A}}$ & $0.082 \pm 0.02 \mathrm{~b}^{\mathrm{A}}$ \\
\hline
\end{tabular}

Different uppercase letters indicate significant differences among different forest types (Cunninghamia lanceolata, Pinus massoniana) of the same stand type (artificial or natural) $(p<0.05)$. Different lowercase letters indicate significant differences among different stand types of the same forest type $(p<0.05)$.

\section{Discussion}

\subsection{Characteristics of Biomass and Carbon Stock of Fallen Trees}

Fallen trees comprise an important functional unit of a forest ecosystem, their stock not only directly affects succession and biodiversity conservation in forest communities [21], but also serves an irreplaceable role in maintaining the stability of nutrient cycling and enhancing the ability to resist interference in a forest ecosystem [22]. Our results indicated that the biomass of fallen trees in Nebf was significantly higher than the biomass of fallen trees in Acf and Ncf. However, the carbon stock of fallen trees manifested a consistent pattern among different forests, Nebf $>A c f>N c f$. We also discovered that the biomass of fallen trees in Nebf in Jiangxi Province was less than that in Abies fargesii forest [23], evergreen broad-leaved forests in the Daming Mountain [24], and other forests [25-28]; but was higher than the biomass of fallen trees in tropical seasonal rain-forests in Xishuangbanna [29], evergreen broad-leaved forests in Guangzhou [30] and natural forests of Castanopsis kawakamii in Sanming [31]. Conversely, the biomass of fallen trees in Ncf was less than that in Pinus tabulaeformis secondary forests in the Qinling Mountains [32], and Korean pine forests in the Changbai Mountains [33]. Compared with Larix gmelinii forests in the Daxing'anling Mountains, the biomass of fallen trees in Ncf was determined to be at the middle level [34]. However, the biomass of fallen trees in Acf was higher than those in coniferous forests in Guangzhou [30], artificial Castanopsis kawakamii forests and Chinese Fir forests in Sanming [31], but less than the biomass of fallen trees in mixed coniferous forests and broad-leaved forests in Guangzhou [30](Table A2). Therefore, the largest amount of biomass and carbon stocks of fallen trees among three forest types (Nebf, Ncf and Acf) in Jiangxi Province was measured for Nebf, which may serve a central role in the carbon cycles in subtropical regions.

Previous studies indicated that artificial forests exhibited a larger planting density and had similarly-aged trees with small disturbances that originated from afforestation and human management [13]; whereas natural forests had predominantly diversely-aged trees with smaller disturbances that originated from human management and afforestation [14]. These findings suggested that stand origin would certainly impact tree lodging, but the underlying mechanisms were still unclear. We found that the biomass and carbon stock of fallen trees in Nclf were significantly higher than that in $A c l f$, and that the biomass and carbon stock of fallen trees in Npf were also significantly larger than that in Apf; however, no significant differences between Aclf and Apf, or between Nclf and Npf were observed (Table 2). This finding further suggested that stand origin was the major factor that affected fallen tree biomass and carbon stock in Jiangxi Province. However, the forest types (neither Aclf and Apf, nor Nclf and Npf) had no significant effect on the biomass and carbon stock of fallen trees in subtropical forests. The disturbance and management of afforestation in artificial forests were significantly greater than those in natural forests. Although the biomass of fallen trees in artificial forests was significantly less than that in natural forests, the average forest age between artificial forests and natural forests was relatively similar (Table 1), which indicated that the stand origin had a significant impact on tree lodging. 


\subsection{Diameter Class Distribution of Fallen Trees}

The diameter class affected the decomposition and stock of fallen trees. It is generally known that smaller diameter classes of fallen trees with greater contact area with the ground yield faster decomposition rates [2]; whereas larger diameter classes of fallen trees exhibit a slower rate of decomposition. These may allow the storage of a greater carbon stock of fallen trees in a forest ecosystem [2,3]. The distribution of the diameter class of fallen trees was affected by the structural composition of forest stands, site conditions and disturbance [32-34]. For example, Liu et al. [35] reported that coarse woody debris in evergreen broadleaved forests after an ice storm in Northern Guangdong Province yielded a large diameter class of forest stands on windward slopes that facilitated the formation of a large number of fallen trees, whereas the small diameter class of forest stands on leeward slopes was affected by low temperature and frost damage [35]. In native forests in the Ailao Mountains, fallen trees and stumps were primarily associated with large diameter class: the majority exceeded $40 \mathrm{~cm}$, and the fallen trees in secondary forests were primarily associated with a small diameter class [28]. Our results revealed that the fallen trees in artificial forests were associated with small diameter class, in which the diameter was always less $10 \mathrm{~cm}$ (Table 3), and the ratios of fallen trees in natural forests with small diameters were less than those in artificial forests. Each diameter class allocation for natural forests was more uniform compared with the diameter class for artificial forests (Table 4). This result may be due to the observation that artificial forests were predominantly similarly aged with densities that exceeded the densities of natural forests (Table 1). Therefore, the mortality of a small diameter class was greater as a result of competition in forest ecosystems, and the small diameter class of fallen trees was easily attributed to fallen trees due to snow and pests. These results suggested that the transformation from natural forest to artificial forest by degradation not only altered the composition of stand and communities, but also significantly changed the composition and diameter class distribution of fallen trees.

\subsection{Differences in the Decomposition of Fallen Trees}

The decomposition of fallen trees serves an important role in the function of a forest ecosystem [36-38]. The decomposition of fallen trees has a close relationship with the tree species, diameter class and forest land environment $[39,40]$. The biological, physical and chemical properties of wood vary among tree species, which creates differences in the decomposition process of fallen trees. The decomposition of fallen trees is dependent on forest land temperature, humidity, light and biological environment. Conversely, the decomposition of fallen trees was found to be closely related to the microbial community [41], fungal richness [42,43], and microbial environment [44,45], as well as the densities of fallen trees, nutrient concentrations and ratios $[39,44,46]$. Using decay class to classify the decomposition of fallen wood can reflect the community history and function. Our results indicated that the biomass of fallen trees with mild, moderate and heavy decay in artificial forests significantly differed; however, the biomass of fallen trees with moderate decay in $N c f$ and Nebf was significantly higher than in fallen trees with mild and heavy decay (Figure 3), which suggests that the natural forest was dominated by the fallen trees with moderate decay class. The biomass of fallen trees with mild decay was neither significant among forest types within stand origin nor among stand origin within forest types (Table 5). However, the biomass of fallen trees with moderate and heavy decay was significantly different among stand origin (Aclf vs. Nclf, Apf vs. Npf), but there was no significant difference among forest types within stand origin (Aclf vs. Apf, Nclf vs. Apf) (Table 5). This finding was consistent with the previous results for the subtropical forests of China [26,47-49], which illustrates that stand origin and near-natural restoration significantly influence the decomposition of fallen trees in mid-subtropical forests.

\section{Conclusions}

The amounts of biomass and carbon stock of fallen trees in natural evergreen broadleaf forests were significantly larger than those in coniferous forests, and the amounts of biomass and carbon stock 
of fallen trees in Ncf were significantly larger than those in Acf in subtropical China. The effects of stand origin on the large diameter classes (II, III and IV) of fallen trees were greater than those on the small diameter class (I). After the development of forest succession and near-natural restoration, the mortalities of the fallen trees in the small diameter class decreased. Stand origin is a major factor that affects the biomass and carbon stock of fallen trees in Jiangxi Province. Differences in stand origin also play a primary role in the decomposition of fallen trees and carbon cycles in subtropical forests. Additional studies are necessary to investigate the underlying mechanisms of fallen tree decomposition with respect to stand origin and near-natural restoration.

Acknowledgments: This study was financially supported by Strategic Priority Research Program of the Chinese Academy of Sciences (Grant No. XDA05050205) and Gan-Po 555 Talent Project Funding of Jiangxi Province. We also thank the two anonymous reviewers' detailed and constructive suggestions and comments for improving this manuscript.

Author Contributions: The authors contributed equally to investigating, collecting data and completing the project. Chunsheng Wu, Xiaohua Wei, Yuanqiu Liu and Qinglin Li were responsible for the research design and wrote early drafts of the manuscript with contributions from Xiaohua Wei, Xiaodong Li, Liangying Liu, Chunjie Shu and Qifeng Mo through the editorial process.

Conflicts of Interest: The authors declare no conflict of interest.

\section{Appendix 1}

Table A1. Standing trees ratios (\%) of diameter class in artificial and natural forests.

\begin{tabular}{ccccc}
\hline \multirow{2}{*}{ Stand Types (Plots) } & \multicolumn{4}{c}{ Diameter Class Ratios } \\
\cline { 2 - 5 } & $\mathbf{5 - 1 0} \mathbf{~ c m}$ & $\mathbf{1 0 - 1 5} \mathbf{~ c m}$ & $\mathbf{1 5 - 2 0} \mathbf{~ c m}$ & $\geqslant \mathbf{2 0} \mathbf{~ c m}$ \\
\hline Aclf (10) & $66.1 \pm 7.4 \mathrm{a}^{\mathrm{A}}$ & $19.8 \pm 4.2 \mathrm{a}^{\mathrm{A}}$ & $8.4 \pm 1.9 \mathrm{a}^{\mathrm{A}}$ & $5.7 \pm 1.3 \mathrm{a}^{\mathrm{A}}$ \\
Apf (10) & $41.4 \pm 4.5 \mathrm{a}^{\mathrm{B}}$ & $48.8 \pm 5.2 \mathrm{a}^{\mathrm{B}}$ & $6.8 \pm 1.5 \mathrm{a}^{\mathrm{A}}$ & $3.0 \pm 0.7 \mathrm{a}$ \\
Nclf (10) & $49.7 \pm 6.3 \mathrm{~b}^{\mathrm{A}}$ & $30.1 \pm 4.2 \mathrm{~b}^{\mathrm{A}}$ & $15.8 \pm 3.6 \mathrm{~b}^{\mathrm{A}}$ & $4.4 \pm 1.1 \mathrm{a}^{\mathrm{A}}$ \\
Npf (10) & $37.2 \pm 4.9 \mathrm{a}^{\mathrm{B}}$ & $27.7 \pm 4.1 \mathrm{~b}^{\mathrm{A}}$ & $23.5 \pm 3.7 \mathrm{~b}^{\mathrm{B}}$ & $11.6 \pm 2.9 \mathrm{~b}^{\mathrm{B}}$ \\
Nebf (20) & $49.8 \pm 6.3$ & $20.3 \pm 4.3$ & $9.5 \pm 2.8$ & $20.4 \pm 3.3$ \\
\hline
\end{tabular}

The starting measurement of standing trees DBH was $5 \mathrm{~cm}$. Different uppercase letters indicate significant differences among different forest types (Cunninghamia lanceolata, Pinus massoniana) of the same stand type at $p<0.05$. Different lowercase letters indicate significant differences among different stand types for the same forest type $(p<0.05)$.

Table A2. Comparison of fallen tree biomass in various forest ecosystems.

\begin{tabular}{ccc}
\hline Forest Type, China & Fallen Trees (mg/ha) & References \\
\hline Abies fargesii forest in the QinlingMountains & 15.850 & Li, et al., 1998 [23] \\
\hline $\begin{array}{c}\text { Evergreen broad-leaved forests in the Daming Mountains } \\
\text { Tropical seasonal rain forest in Xishuangbanna of } \\
\text { southwestern China }\end{array}$ & 22.945 & Liang, et al., 2012 [24] \\
\hline $\begin{array}{c}\text { Larix gmelinii forests in Daxing'anling Mountains of } \\
\text { northeast China }\end{array}$ & 4.500 & Deng, et al., 2012 [29] \\
\hline $\begin{array}{c}\text { Monsoon evergreen broad-leaved forest in the Dinghushan } \\
\text { Nature Reserve }\end{array}$ & 0.489 6.683 & Wang, et al., 2012 [34] \\
\hline $\begin{array}{c}\text { Natural Quercus aliena forest in the Xiaolong Mountains, Gansu } \\
\text { Pinus tabulaeformis forest in the Xiaolong Mountains, Gansu }\end{array}$ & 32.810 & Yang, et al., 2011 [25] \\
\hline $\begin{array}{c}\text { Moist evergreen broad-leaved forest in the Ailao Mountains of } \\
\text { Yunnan Province }\end{array}$ & 6.72 & He, et al., 2011 [27] \\
\hline $\begin{array}{c}\text { Pinus tabulaeformis Secondary forest in the Qinling Mountains } \\
\text { Toxicodendron vernicifluum forest in the Qinling Mountains }\end{array}$ & $\begin{array}{c}5.740 \\
2.510\end{array}$ & Yang, et al., 2007 [28] \\
\hline $\begin{array}{c}\text { Mid-subtropical evergreen broad-leaved forest in Wanmulin } \\
\text { Nature Reserve, Fujian }\end{array}$ & 17.909 & Yuan, et al., 2012 [32] \\
\hline $\begin{array}{c}\text { Broad-leaved and Korean pine mixed forest in Changbai } \\
\text { Mountains of Jilin Province }\end{array}$ & $7.900 ~ 16.200$ & He, et al., 2010 [26] \\
\hline
\end{tabular}


Table A2. Cont.

\begin{tabular}{ccc}
\hline Forest Type, China & Fallen Trees (mg/ha) & References \\
\hline Conifer forest in Guangzhou & 0.163 & \\
Mixed conifer and broad-leaved in Guangzhou & 2.063 & Zhang, et al., 2009 [30] \\
Evergreen broad-leaved forest in Guangzhou & 3.353 & \\
\hline Natural forest of Castanopsis kawakamii in Sanming, Fujian & 1.320 & Yang, et al., 2005 [31] \\
Artificial forest of Castanopsis kawakamii in Sanming, Fujian & 0.460 & \\
Artificial forest of Chinese Fir in Sanming,Fujian & 0.230 & This study \\
\hline Natural evergreen broadleaf forest in subtropical, China & 11.293 & \\
Natural coniferous forest in subtropical, China & 0.847 & \\
Artificial coniferous forests in subtropical, China & &
\end{tabular}

\section{References}

1. Harmon, M.E.; Franklin, J.F.; Swanson, F.J.; Sollins, P.; Gregory, S.V.; Lattin, J.D.; Anderson, N.H.; Cline, S.P.; Aumen, N.G.; Sedell, J.R.; et al. Ecology of coarse woody debris in temperate ecosystems. In Ecology of Coarse Woody Debris in Temperate Ecosystems; Macfadyen, A., Ford, E.D., Eds.; Academic Press: London, UK, 1986; pp. 133-302.

2. Harmon, M.E.; Nadelhoffer, K.J.; Blair, J.M. Measuring decomposition, nutrient turnover, and stores in plant litter. In Standard Soil Methods for Long Term Ecological Research; Robertson, G.P., Coleman, D.C., Bledsoe, C.S., Sollins, P., Eds.; Oxford University Press: New York, NY, USA; Oxford, UK, 1999; pp. 202-234.

3. Harmon, M.E.; Sexton, J. Guidelines for Measurements of Woody Detritus in Forest Ecosystems: US LTER Publication No. 20; US LTER Network Office; University of Washington: Seattle, WA, USA, 1996.

4. James, T.W.; William, K.; Cornwell, W.K.; Johannes, H.C.; Cornelissen, J.H.C.; Amy, E.Z.; Christian, W.; David, A.C. Global meta-analysis of wood decomposition rates: A role for trait variation among tree species? Ecol. Lett. 2009, 12, 45-56.

5. Woodall, C.W.; Liknes, G.C. Relationships between forest fine and coarse woody debris carbon stocks across latitudinal gradients in the United States as an indicator of climate change effects. Ecol. Indic. 2008, 8, 686-690. [CrossRef]

6. Harmon, M.E.; Fasth, B.; Woodall, C.W.; Sexton, J. Carbon concentration of standing and downed woody detritus: Effects of tree taxa, decay class, position, and tissue type. For. Ecol. Manag. 2013, 291, $259-267$. [CrossRef]

7. Galik, C.S.; Mobley, M.L. A virtual "field test" of forest management carbon offset protocols: The influence of accounting. Mitig. Adapt. Strateg. Glob. Chang. 2009, 14, 677-690. [CrossRef]

8. Shawn, F.; Amy, M.M.; John, B.B.; Anthony, W.D.; Laura, K.; Brian, J.P.; Christopher, W.W.; John, B. Woody debris volume depletion through decay: Implications for biomass and carbon accounting. Ecosystems 2013, $16,1262-1272$.

9. Ranius, T.; Caruso, A.; Jonsell, M.; Juutinen, A.; Thor, G.; Rudolphi, J. Dead wood creation to compensate for habitat loss from intensive forestry. Biol. Conserv. 2014, 169, 277-284. [CrossRef]

10. Li, D.; Chen, H.W.; Li, G.Q.; Yang, B.; Meng, M.; Shi, F.Q. Comparative analysis of artificial forest and natural forest in China. For. Invent. Plan. 2011, 36, 59-63. (In Chinese).

11. Jia, Z.B. China Forest Resources Report-Seventh National Forest Resource Inventory; China Forestry Publishing House: Beijing, China, 2009. (In Chinese)

12. Zhu, J.J.; Liu, Z.G. A review on disturbance ecology of forest. Chin. J. Appl. Ecol. 2004, 15, $1703-1710$. (In Chinese).

13. James, L.H.; Michael, D.U.; Dale, D.W. Impacts of prescribed fire frequency on coarse woody debris volume, decomposition and termite activity in the longleaf pine flat woods of Florida. Forests 2012, 3, 317-331.

14. Matthew, B.R.; Christopher, W.W.; Shawn, F.; Anthony, W.D.; Grant, M.D.; Kenneth, E.S. Residence times and decay rates of downed woody debris biomass/carbon in eastern US forests. Ecosystems 2014, 17, 765-777.

15. West, A.J.; Lin, C.W.; Lin, T.C.; Hilton, R.G.; Liu, S.H.; Chang, C.T.; Lin, K.C.; Galy, A.; Sparkes, R.B.; Hovius, N. Mobilization and transport of coarse woody debris to the oceans triggered by an extreme tropical storm. Limnol. Oceanogr. 2011, 56, 77-85. [CrossRef] 
16. Darcey, K.I.; Creighton, M.L.; Christian, P.G. Coarse woody debris carbon storage across a mean annual temperature gradient in tropical montane wet forest. For. Ecol. Manag. 2013, 291, 336-343.

17. Paul, C.S.; Creighton, M.L.; Christian, P.G.; Gregory, P.A. Ecosystem carbon storage does not vary with mean annual temperature in Hawaiian tropical montane wet forests. Glob. Chang. Biol. 2014, 20, 2927-2937.

18. Li, X.; OuYang, X.Z.; Liu, Q.J. Carbon storage of forest vegetation and its geographical pattern in China's Jiangxi Province during 2001-2005. J. Nat. Resour. 2011, 26, 655-665. (In Chinese).

19. Sollins, P. Input and decay of coarse woody debris in coniferous stands in western Oregon and Washington. Can. J. For. Res. 1982, 12, 18-28. [CrossRef]

20. Meng, X.Y. Holzmesslehre; China Forestry Publishing House: Beijing, China, 1998. (In Chinese)

21. Graham, S.A. The felled tree trunk as an ecological unit. Ecology 1925, 6, 397-411. [CrossRef]

22. Storry, K.A.; Weldrick, C.K.; Mews, M.; Zimmer, M.; Jelinski, D.E. Intertidal coarse woody debris: A spatial subsidy as shelter or feeding habitat for gastropods? Estuar. Coast. Shelf Sci. 2006, 66, 197-203. [CrossRef]

23. Li, L.H.; Dang, G.D.; Wang, T.J.; Zhao, L.G. Coarse woody debris in an Abies fargesii forest in the Qinling Mountains. Acta Phytoecol. Sin. 1998, 22, 434-440. (In Chinese).

24. Liang, H.W.; Wen, L.H.; Wen, Y.G.; Liang, J.S.; Huang, D.J. Storage characteristics of woody debris in the evergreen broad-leaved forests after a frozen disaster in 2008 in the Daming Mountain, China. Sci. Silvae Sin. 2012, 48, 11-16. (In Chinese).

25. Yang, F.F.; Li, Y.L. Coarse woody debris biomass in a monsoon evergreen broad-leaved forest in the Dinghushan Nature Reserve, China. Chin. J. Appl. Environ. Biol. 2011, 17, 750-752. (In Chinese).

26. He, X.D.; Yang, Z.J.; Guo, J.F.; Chen, G.S.; Ma, S.G.; Zhang, B. Composition and storage of woody debris in mid-subtropical evergreen broad-leaved forest in Wanmulin Nature Reserve. J. Subtrop. Resour. Environ. 2010, 5, 46-52. (In Chinese).

27. He, F.; Wang, D.X.; Zhang, S.Z.; Liu, W.Z.; Shen, Y.Z.; Hu, Y.N. Reserves of litter and woody debris of two main forests in the Xiaolong Mountains, Gansu, China. Chin. J. Appl. Environ. Biol. 2011, 17, 46-50. (In Chinese). [CrossRef]

28. Yang, L.P.; Liu, W.Y.; Yang, G.P.; Ma, W.Z.; Li, D.W. Composition and carbon storage of woody debris in moist evergreen broad-leaved forest and its secondary forests in Ailao Mountains of Yunnan Provinve. Chin. J. Appl. Ecol. 2007, 18, 2153-2159. (In Chinese).

29. Deng, Y.; Zheng, W.F.; Deng, X.B.; Li, Y.W. Storage of coarse wood debris and its spatial distribution in a tropical seasonal rain forest in Xishuangbanna of Southwest China. Chin. J. Ecol. 2012, 31, 261-270. (In Chinese).

30. Zhang, X.Y.; Guan, D.S.; Zhang, H.D. Characteristics of storage and decomposition of coarse woody debris (CWD) under three forests in Guangzhou. Acta Ecol. Sin. 2009, 29, 5227-5236. (In Chinese).

31. Yang, Y.S.; Guo, J.F.; Lin, P.; He, Z.M.; Chen, G.S. Carbon and nutrient pools of coarse woody debris in a natural forest and plantation in subtropical China. Sci. Silvae Sin. 2005, 41, 7-11. (In Chinese).

32. Yuan, J.; Cai, J.; Hou, L.; Zhang, S.X. Storage and decomposition of fallen wood in a Pinus tabulaeformis secondary forest at Huoditang forest region in the Qinling Mountains. Sci. Silvae Sin. 2012, 48, 141-146. (In Chinese).

33. Dai, L.M.; Xu, Z.B.; Chen, H. Storage dynamics of fallen trees in the broad-leaved and Korean pine mixed forest. Acta Ecol. Sin. 2000, 20, 412-416. (In Chinese).

34. Wang, F.; Zhang, Q.L.; Wang, B.; Bao, Y.; Gao, X.W.; Li, D.Y.; Ye, D.M. Storage and characteristics of coarse woody debris in different aged natural Ledum palustre-Larix gmelinii forests in Daxing'anling Mountains of Northeast China. Chin. J. Ecol. 2012, 31, 2981-2989. (In Chinese).

35. Liu, Z.X.; Zhang, L.; OU, Y.D.; Sun, D.; Su, Z.Y. The composition and structure of coarse woody debris in the evergreen broadleaved forest after ice storm in northern Guangdong Province. J. Southwest For. Univ. 2011, 31, 18-23. (In Chinese).

36. Chambers, J.Q.; Schimel, J.P.; Nobre, A.D. Respiration from coarse wood litter in central Amazon forests. Biogeochemistry 2001, 52, 115-131. [CrossRef]

37. Jomura, M.; Kominami, Y.; Tamai, K.; Miyama, T.; Goto, Y.; Dannoura, M.; Kanazawa, Y. The carbon budget of coarse woody debris in a temperate broad-leaved secondary forest in Japan. Tellus B 2007, 59, $211-222$. [CrossRef]

38. Woodall, C.W. Carbon flux of down woody materials in forests of the north central United States. Int. J. For. Res. 2010, 2010, 1-9. [CrossRef] 
39. Bantle, A.; Borken, W.; Matzner, E. Dissolved nitrogen release from coarse woody debris of different tree species in the early phase of decomposition. For. Ecol. Manag. 2014, 334, 277-283. [CrossRef]

40. Bantle, A.; Borken, W.; Ellerbrock, R.H.; Schulze, E.D.; Weisser, W.W.; Matzner, E. Quantity and quality of dissolved organic carbon released from coarse woody debris of different tree species in the early phase of decomposition. For. Ecol. Manag. 2014, 329, 287-294. [CrossRef]

41. Pasanen, H.; Junninen, K.; Kouki, J. Restoring dead wood in forests diversifies wood-decaying fungal assemblages but does not quickly benefit red-listed species. For. Ecol. Manag. 2014, 312, 92-100. [CrossRef]

42. Poznanovic, S.K.; Lilleskov, E.A.; Webster, C.R. Sharing rotting wood in the shade: Ectomycorrhizal communities of co-occurring birch and hemlock seedlings. Mycorrhiza 2015, 25, 153-164. [CrossRef] [PubMed]

43. Witoon, P.; Tiemo, K.; Michael, S.; Jürgen, B.; François, B.; Dirk, K. Comparing fungal richness and community composition in coarse woody debris in Central European beech forests under three types of management. Mycol. Progress 2014, 13, 959-964.

44. Fukasawa, Y.; Takahashi, K.; Arikawa, T.; Hattori, T.; Maekawa, N. Fungal wood decomposer activities influence community structures of myxomycetes and bryophytes on coarse woody debris. Fungal Ecol. 2015, 14, 44-52. [CrossRef]

45. Toshiyuki, O.; Yoko, S.; Mitsuru, H.; Yuichiro, Y.; Jia, S.G.; Yasuo, I.; Hiroshi, K. Role of coarse woody debris in the carbon cycle of Takayama forest, central Japan. Ecol. Res. 2014, 29, 91-101.

46. Guo, J.F.; Chen, G.S.; Xie, J.S.; Yang, Z.J.; Yang, Y.S. Patterns of mass, carbon and nitrogen in coarse woody debris in five natural forests in southern China. Ann. For. Sci. 2014, 71, 585-594. [CrossRef]

47. Liu, Y.Y.; Jin, G.Z. Spatial point pattern analysis for coarse woody debris in a mixed broadleaved-Korean pine forest in Xiaoxing'an Mountains, China. Acta Ecol. Sin. 2010, 30, 6072-6081. (In Chinese).

48. Zhao, P.W.; Hai, L.; Song, C.L.; Su, R.N.; Zhou, M.; Wei, J.S.; Wang, S.S. Study of fallen woods in Larix gmelinii forest of Daxinganling Mountain. J. Arid Land Resour. Environ. 2010, 24, 173-177. (In Chinese).

49. Wang, J.F.; Zheng, X.X.; Wang, T.N.; Yang, F.J. Storage of dead woods and effect of dead woods on regeneration of PICEA-Fir forest in Changbai Mountains. Acta Agric. Boreali-Sin. 2004, 19, 45-49. (In Chinese).

(C) 2015 by the authors; licensee MDPI, Basel, Switzerland. This article is an open access article distributed under the terms and conditions of the Creative Commons by Attribution (CC-BY) license (http://creativecommons.org/licenses/by/4.0/). 